\title{
Visual Recovery After Decompression Surgery of Skull Base Meningioma: A Case Report
}

\author{
Maryam Naser MD* and Nafiseh Hashemi MD
}

Neuro-ophthalmology Clinic, Hashemi Eye Care, USA

*Corresponding author: Maryam Naser MD, Neuro-ophthalmology Clinic, Hashemi Eye

Care, Encino, California, USA.

Received Date: August 10, 2019

Published Date: August 14, 2019

\section{Introduction}

About $30 \%$ of all primary brain tumors are meningioma. It occurs in women twice than men. Several cases have been reported about the relationship between visual acuity disturbance and meningioma. Here, we present a case with vision loss caused by skull base meningioma for unknow duration of time which surprisingly recovered after successful resection of the tumor.

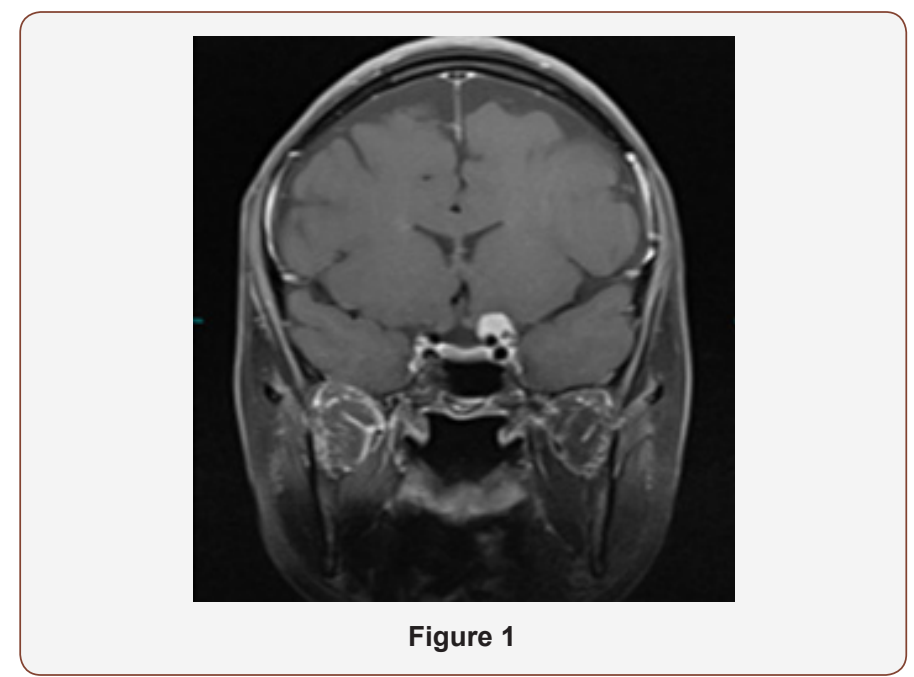

The patient is a 39-year-old female who was referred to neuroophthalmology office on November 2018 for the optic atrophy of left eye. She had noticed vision less in the left eye when she went to DMV for renewal of her license. She was not aware of the duration of vision loss. There was no history of pain with eye movement, trauma to the eye, infectious, and or inflammatory disease. She denied headaches, diplopia, numbness or tingling, and low back pain. Her past medical and surgery history was not significant. In eye exam, her vision was 20/25 on right and 20/150 left eye. Color vision was $11 / 11$ in right and 1/11 in left eye. She had RAPD in left eye. Visual field of the right eye was normal. She was not able to do visual field on the left side. OCT optic nerve showed mild
RNFL thinning on the left eye. MRI brain and orbit showed an enhancing mass impressing on the posterior aspect of the left optic nerve showing a slight dural tail measuring $13.1 \times 11.1 \times 12.2 \mathrm{~mm}$, consistent with meningioma. The mass encases left internal artery. She was referred to neurosurgeon for tumor resection. She gained back some of her vision immediately after surgery. The patient came back for follow up on December 2018. Her vision was 20/20 in both eyes and color vision on left eye was improved to 5/11 (Figure 1,2).

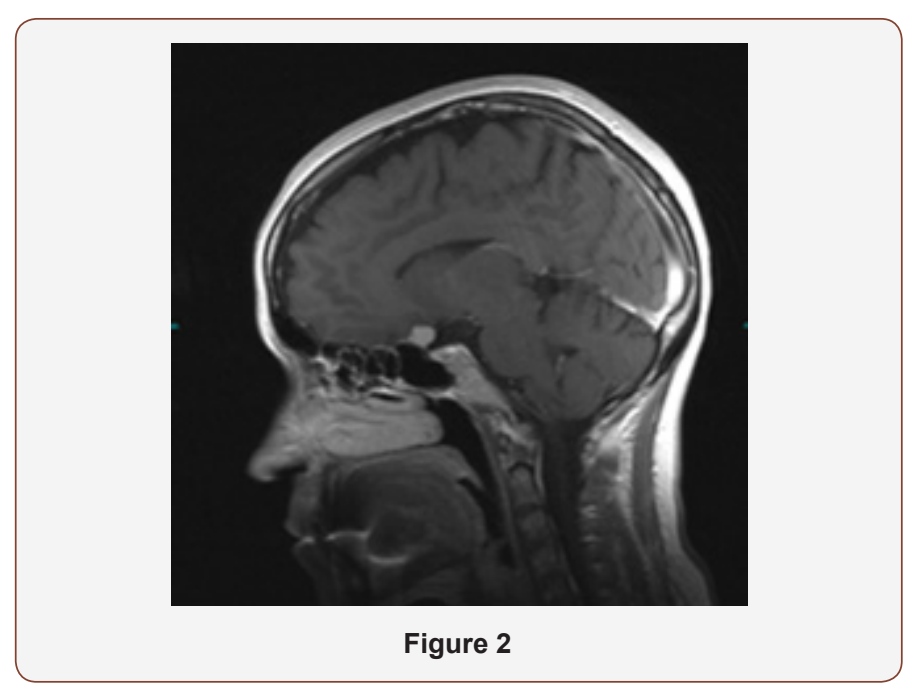

\section{Discussion}

A meningioma is a tumor of covering membranes of the brain and spinal cord. They are usually slow-growing and $90 \%$ benign. Headaches, vision problems, seizures, one sided weakness, and speech problems are the most common symptoms of meningioma. Some studies have been reported the relation between meningioma and visual acuity disturbance. Early diagnosis and tumor resection are necessary because visual recovery will be complicated once it is disturbed. In case, if the tumor progresses and causes complete blindness, even a surgical removal cannot help to improve the 
vision loss. In general, patients with meningioma on the lateral and superolateral sphenoid ridge usually have better visual prognosis compare to the tumors that are encroaching the optic canal [13]. Prognosis of visual acuity disturbance caused by meningioma depends on preoperative duration of symptoms and extent of visual impairment [4]. A case was reported by Tamura $R$, et al. demonstrated improvement in visual acuity, after tumor resection despite long-term blindness associated with tumor invasion into the optic canal [5]. In our presented case, vision loss was completely recovered after tumor resection. Although, the duration of visual impairment caused by tumor was unknown to the patient and she had acute awareness of vision loss in DMV. Based on a few case reports, there is no correlation between the extend of the nerve pallor and RNFL thinning to the visual recovery. But we believe, the severity and the duration of vision loss due to compression is playing an important factor in the final visual recovery. A study was done in a group of 23 patients with suprasellar meningiomas and central visual acuity loss. Improvement in vision occurred within the first several weeks after operation and further return of vision was not noted after one year [6]. The result in other study of 65 patients who underwent surgery of a medial sphenoid wing meningiomas resection showed that 46 (71\%) maintained their preoperative visual acuity, five (8\%) had improved vision, and 14 (22\%) had worsened vision at last follow-up [7]. We suggest that the decompression surgery should be done as soon as possible to raise the chance of recovery.

In conclusion, vision loss due to compressive effect of meningioma may be reversible. MRI brain and orbit are essential part of evaluation of optic atrophy. There is not enough evidence about the prediction of visual recovery after decompression surgery of a meningioma. Despite of the presence of RAPD and optic atrophy, there is still chance of visual recovery after decompression surgery.

\section{Acknowledgment}

None.

\section{Conflicts of Interest}

No conflict of interest.

\section{References}

1. Galal A, Faisal A, Al Werdany M, El Shehaby A, Lotfy T, et al. (2010) Determinants of postoperative visual recovery in suprasellar meningioma. Acta Neurochir (Wien) 152(1): 69-77.

2. Mariniello G, Bonavolonta G, Tranfa F, Maiuri F (2013) Management of the optic canal invasion and visual outcome in spheno-orbital meningiomas. Clin Neurol Neurosurg 115(9): 1615-1620.

3. Wang CW, Li YY, Zhu SG, Yang Y, Wang HW, et al. (2011) Surgical management and evaluation of prognostic factors influence postoperative visual outcome of suprasellar meningiomas. World Neurosurg 75(2): 294-302.

4. Mariniello G, De Divitiis O, Bonavolonta G, Maiuri F (2013) Surgical unroofing of the optic canal and visual outcome in basal meningiomas. Acta Neurochir 155(1): 77-84.

5. Tamura R, Takahashi S, Horikoshi T, Yoshida K (2016) Improvement of long-term blindness caused by compression from inner-third sphenoid wing meningioma after optic canal decompression. Surg Neurol Int 7: 67.

6. Gregorius FK, Hepler RS, Stern WE (1975) Loss and recovery of vision with suprasellar meningiomas. J Neurosurg 42(1): 69-75.

7. Chaichana KL, Jackson C, Patel A, Miller NR, Subramanian P, et al. (2012) Predictors of Visual Outcome Following Surgical Resection of Medial Sphenoid Wing Meningiomas. J Neurol Surg B Skull Base 73(5): 321-326. 